\title{
Adenocarcinoma In Situ
}

National Cancer Institute

\section{Source}

National Cancer Institute. Adenocarcinoma In Situ. NCI Thesaurus. Code C4123.

A lesion in which the normally situated glands are partially or completely replaced by atypical cells with malignant characteristics. 